\title{
Factors influencing repair of dental restorations with resin composite
}

\author{
This article was published in the following Dove Press journal: \\ Clinical, Cosmetic and Investigational Dentistry \\ 17 October 2014 \\ Number of times this article has been viewed
}

\author{
Igor R Blum' \\ Christopher D Lynch² \\ Nairn HF Wilson ${ }^{3}$ \\ 'Maurice Wohl Dental Academy, King's \\ College London Dental Institute, \\ London, UK; ${ }^{2}$ School of Dentistry, \\ College of Biomedical and Life \\ Sciences, Cardiff University, Cardiff, \\ Wales; ${ }^{3}$ King's College London Dental \\ Institute, London, UK
}

\begin{abstract}
The presentation of patients with dental restorations that exhibit minor defects is one of the commonest clinical situations in the practice of general dentistry. The repair of such restorations, rather than replacement, is increasingly considered to be a viable alternative to replacement of the defective restoration. This paper considers factors influencing the repair of direct restorations, including indications and details of relevant techniques, based on the best available knowledge and understanding of this important aspect of minimal intervention dentistry. Practitioners who do not consider repair before deciding to replace restorations that present with limited defects are encouraged to consider including repair in the treatment options in such situations. The effective repair of direct restorations can greatly influence the rate of descent down the "restorative death spiral".
\end{abstract}

Keywords: restoration repair, minimally invasive dentistry

\section{Introduction}

Direct restorations, in common with all other forms of restorations, suffer deterioration as a result of "wear and tear", and may be susceptible to secondary caries in clinical service. Defects in restorations and lesions of secondary caries adjacent to restoration margins are two of the most frequent clinical observations in general dental practice. Replacement of restorations constitutes around half of the treatments performed by general dental practitioners. ${ }^{1,2}$ However, total restoration replacement may be regarded as excessively interventional in many situations, since in the large majority of cases, most of the restoration $(>80 \%)$ may be found to be clinically and radiographically sound. ${ }^{3,4}$ Furthermore, restoration replacement invariably results in acceleration of the "restoration death spiral", ${ }_{5}^{5}$ with weakening of the remaining tooth structure through the unnecessary removal of healthy tooth tissue in locations often distant from the site of the deteriorating restoration. An additional risk associated with restoration replacement is unnecessary and potentially fatal insult to the pulp. Consequently, good decision-making in respect of "defective" restorations is central to effective restorative treatment planning, particularly given the growing body of evidence confirming the value and importance of procedures to repair defective restorations.

Diagnosis of secondary caries is inconsistent between dental practitioners, and often not based on objective criteria. ${ }^{6-9}$ If in doubt, most general dental practitioners adopt a "defensive dentistry" approach by choosing replacement as opposed to one of the range of minimal intervention options, including systematic monitoring of such restorations, ie, if in doubt, wait and watch rather than take it out. Decisions to replace restorations with limited defects are particularly common for restorations
Correspondence: Igor R Blum Maurice Wohl Dental Academy, $\mathrm{KCL} / \mathrm{KCH}$ West Norwood Health \& Wellbeing Centre 25 Devane Way, West Norwood, London SE27 ODF, UK Email igor.blum@nhs.net 
not placed by the evaluating practitioner, ${ }^{10}$ as demonstrated in analyses of the patterns of provision of dental restorations within National Health Service dental services in the UK and in large North American studies. ${ }^{11,12}$ For example, within a cohort of over 300,000 patients in 2002, Bogacki et al noted that the probability of survival of both posterior amalgam and resin composite restorations was in excess of $90 \%$ over 5 years, but that this survival rate dropped to $60 \%$ (for both types of restoration) when patients changed dentist. ${ }^{12}$ A more recent dental practice-based research study, involving 197 clinicians in the USA and Scandinavian countries, and close to 10,000 restorations, indicated that when considering treatment options for restorations with localized defects, in over $75 \%$ of cases the practitioners choose replacement rather than repair. ${ }^{13}$ The same study confirmed that decisions to replace restorations with limited defects are particularly common for restorations not placed by the evaluating practitioner.

Identification of a defect in a restoration, and the subsequent decision-making, tends to be limited to visual and tactile examinations; however, the management plan for the restored tooth should be based on risk assessment, including assessment of further caries, structural deterioration, catastrophic failure, and loss of pulp vitality. The recognition of one or more limited defects in a restoration does not necessarily mean that the restoration has suffered irreversible damage and requires immediate replacement. Most defects in restorations, other than those caused by sudden impact fracture, develop gradually over extended periods of time, ${ }^{13}$ providing the clinician with an opportunity to address the cause of the problem and undertake some form of minimal intervention to correct the defect or defects, thereby extending the life expectancy of the restoration. Minimal intervention treatment may include repair of the defects, especially if the defects are localized and accessible, or simple refurbishment of the restoration if the defects are superficial. ${ }^{14,15}$ The main advantage of such approaches to the management of limited defects in restorations is the avoidance of unnecessary removal of intact tooth tissue, leaving restored teeth more able to withstand loading in function and, as a consequence, an improved prognosis. Furthermore, a replacement restoration is always larger than the one replaced, and larger restorations perform less well in clinical service than smaller restorations. Notwithstanding the benefits of restoration repair, restoration replacement may be inevitable when a restoration is undermined by extensive caries or in the presence of cracked cusps adjacent to the existing restoration. Such cracks are not detectable on radiographs and often asymptomatic, even when the crack is quite advanced. In such cases, removing the entire restoration facilitates detection of cracked cusps where the crack typically propagates from the internal line angles of existing restorations.

\section{Terminology and treatment options}

The terms glazing, sealing, refurbishment, and repair are often misused in the literature. Setcos et $\mathrm{al}^{16}$ described these four terms clearly, together with indications for the application of each approach. These were subsequently redefined by the World Dental Federation (FDI). ${ }^{17}$ There are, in general, four approaches to the management of defective restorations, as follows: ${ }^{18}$

- no treatment (monitoring), indicated if only minor shortcomings, eg, unfavorable color/staining or suboptimal margins are present, with no clinical disadvantages if untreated

- refurbishment, indicated if shortcomings may be corrected without damage to the tooth, eg, removal of overhangs, recontouring the surface, removal of discoloration, smoothening or glazing of surface, including sealing of pores and small gaps, without adding new restorative material (except glaze or bonding)

- repair, indicated mainly in the event of localized shortcomings that are clinically unsatisfactory and no longer acceptable; repair is a minimally invasive approach that implies in any case the addition of a restorative material (not only glaze or adhesive), with or without a preparation in the restoration and/or tooth structure ${ }^{17,19}$

- replacement, indicated if generalized or severe problems and intervention are necessary, and a repair is not reasonable or feasible; replacement is the complete removal of the restoration, usually involving more loss of tooth structure.

The many different advantages of repairing rather than replacing a restoration, may be summarized as follows: ${ }^{4,15}$

- preservation of tooth structure

- reduction of potentially harmful effects on the dental pulp

- no need for local anesthesia, provided the repair is not extensive

- reduced risk of iatrogenic damage to adjacent teeth

- reduction in treatment times

- reduced costs to the patient

- good patient acceptance

- increased longevity of the restoration

- slowing of the "restorative death spiral". 
Whilst many failing restorations will eventually require replacement, it is suggested that an increasing number of deteriorating, yet serviceable, restorations may be given extended longevity through refurbishment or repair procedures, provided that the refurbished or repaired restoration satisfies the necessary clinical requirements. ${ }^{1,4,20}$ This opportunity to "buy time" in the quest to make restorations last as long as possible is most encouraging for those minded to adopt and teach minimal intervention techniques. In addition, repair procedures may be much less traumatic or distressing for a patient when compared with replacement procedures, particularly when the patient appreciates that repair rather than replacement is contributing to them having "teeth for life". 21,22

\section{Criteria for repair}

Many criteria play a role in the decision to repair rather than replace a direct restoration with localized defects. These include the patient's caries risk status, the clinical condition of the restored tooth unit, and cost/benefit assessments. Criteria for repair as opposed to complete restoration replacement can be broadly divided into two categories, ie, patient-centered and tooth-specific criteria.

\section{Patient-centered criteria}

Dentally motivated, well informed patients who attend on a regular basis, maintain a good standard of oral health, and in whom restorations can be monitored on a regular basis are good candidates for repair procedures. Another group of suitable candidates for repair procedures comprises patients who have complex medical histories or limited capacity to cooperate. In such patients, the nature of the intervention should be limited in terms of time and complexity. Refurbishment and repair procedures can often be accomplished without the need for local anesthesia and are therefore especially advantageous for patients with complex medical histories and dental anxiety.

It is important that patients understand the nature of the repair procedure and how this procedure differs from restoration replacement. In obtaining informed consent for a repair procedure, it is essential to outline the disadvantages of the replacement strategy in terms of its effect on the prognosis for the restored tooth unit. Similarly, the advantages of the repair strategy in terms of preserving tooth structure and its minimally interventional nature must be elicited.

In deciding whether to repair or replace a restoration in the presence of secondary caries, as diagnosed clinically, the decision to repair rather than replace is likely to be most appropriate in a patient with low caries risk. If the decision is made to replace the restoration in a patient with low caries risk, the preparation will be enlarged unnecessarily and the tooth inappropriately weakened. The longevity of the replacement restoration may suffer uncertainties, let alone the increased risk of more complex and costly subsequent treatment, including endodontic therapy. Notwithstanding these shortcomings, the replacement restoration may be subjected to the same, possibly unrecognized, limitations of the original restoration. A replacement restoration in an unchanged oral environment will, in all probability, be just as susceptible if not more so to failure as the restoration it replaced.

\section{Tooth-specific criteria}

Having ascertained that patient-centered criteria are satisfied, tooth-specific criteria must be considered. To assess tooth-specific criteria, it is important to employ an appropriate selection of investigative techniques, given that no one technique alone is sufficient to provide all the necessary information. Magnification aids for visual inspection and interpretation of radiographic images are considered invaluable in maximizing the sensitivity and specificity of clinical assessments.

\section{Clinical indications Secondary caries}

Secondary caries adjacent to the margin of a restoration should be treated as a new primary lesion. ${ }^{2}$ As with all patients who present with a new caries lesion, preventive measures should be initiated, with operative intervention being limited to situations where the lesion remains active and is progressing through dentine or cavitation. Operative intervention should be minimal and limited to that portion of the adjacent restoration that is undermined by the caries or hinders the access required for effective caries management. The portion of the restoration that presents no clinical or radiographic evidence of failure should be left in place unless there is good clinical indication to resort to total restoration replacement with its various consequences.

\section{Marginal defects and marginal staining}

It is important to realize that the presence of marginal defects does not always indicate the presence of secondary caries. Minor marginal defects in the occlusal surfaces of posterior restorations that are imperceptible to the patient are best monitored, with intervention being delayed until there is evidence of plaque accumulation, food stagnation, or discoloration that may herald active caries. Marginal defects 
in composite restorations, in particular anterior composites, are more problematic because of their tendency to pick up exogenous stain, which compromises esthetic appearance. Refinishing coupled where necessary with refurbishment of the restoration is typically the most effective way to manage such staining successfully. If heavy penetrating staining is present, total restoration replacement may be required to obtain a good esthetic outcome.

\section{Superficial color correction}

If an incorrect shade had been selected in the placement of a composite restoration, this may be managed by resurfacing using a different shade of composite material. Wherever possible, the same restorative material should be used as the composite substrate, but this might not be possible if the restoration was placed by a different practitioner, details of the material used were not recorded in the patient's notes, or the previously placed material is no longer commercially available.

\section{Wear}

As wear of a composite restoration may have been accompanied by passive eruption, or at least tilting of the opposing tooth or teeth, the situation needs to be assessed most carefully. If the wear of the restoration is of a limited nature, confined to the occlusal surface, and space exists to effect a repair, then the situation may be resolved by resurfacing the restoration. If the wear involves a proximal surface and no space exists to restore the anatomic form of the restoration, then an alternative restorative approach may be indicated.

\section{Bulk fracture}

When a patient presents with a bulk fracture of a restoration, particularly soon after restoration placement, it is important to diagnose and eliminate the reason for the fracture; for example, excess occlusal loading. This is necessary to avoid recurring bulk fracture, let alone a fracture involving remaining tooth tissue. Bulk fracture of a restoration that has been in clinical service for many years is likely to be the result of stress fatigue within the restorative material. Observations from qualitative studies on the teaching of restoration repair, including the management of fractured restorations, have indicated that there is a consensus among clinical academics that if the bulk fracture is limited (less than half of the restoration) repair may be indicated; however, the integrity of the remaining portion of the restoration should be carefully assessed. . $^{23-28}$

\section{Fracture of adjacent tooth issue}

Fracture of tooth tissue adjacent to a restoration may occur for various reasons, including parafunctional activity or trauma, or be subsequent to the damaging effects of polymerization stresses in resin composites at the time of restoration placement. A repair may be indicated if the cause of the fracture can be accurately diagnosed and, as a consequence, the risk of further fracture minimized, possibly through a preventive measure such as provision of a mouth guard in, for example, the management of a bruxist patient.

\section{Contraindications to repair}

Contraindications to repair include:

- patient reluctance to accept a repair as an alternative to restoration replacement

- irregular attendance

- high caries risk

- presence of caries undermining most of the existing restoration

- history of failure of a previous repair.

\section{Repair procedures}

According to data from laboratory and clinical investigations published to date, the following recommendations for repair can be made. ${ }^{18,29-32}$

The clinical procedure for the repair of a direct resin composite restoration with one or more limited defects is as follows:

- local analgesia, as indicated clinically

- removal of the defective part of the composite restoration and any adjacent secondary caries

- ensuring adequate moisture control; this can best be achieved with a rubber dam or judicious use of cotton wool rolls and salivary ejectors; either way, it is essential to protect the preparation from contamination

- pulp protection, if indicated, according to contemporary regimes

- preparation of the composite substrate using an intraoral sandblaster (CoJet-Sand; 3M ESPE, Germany; Microetcher, Danville Engineering Company, IA, USA) or a fine grit diamond bur; any exposed tooth tissue should also be prepared by sandblasting, or with a fine grit diamond bur to ensure removal of any residual composite, let alone pellicle to provide a fresh surface to bond onto; the CoJet sandblaster utilizes silica particles and provides a microretentive, "silicatized" surface which, albeit not always necessary, may offer advantages in the 
repair strengths of the repair composite to the composite substrate

- the prepared composite substrate must be acid etched together with the preparation margins for 15-30 seconds and then gently washed and dried using a three-in-one syringe; in addition to producing a favorable substrate surface for bonding, acid etching has a cleansing effect

- if the composite substrate has been treated with the CoJet sandblaster, apply a silane primer and corresponding adhesive (eg, ESPE Sil and Visio-Bond; 3M ESPE, St Paul, MN, USA) to the substrate and an adhesive bonding system to the adjacent tooth tissues and preparation margins, according to manufacturer's directions; if the substrate has been prepared with a fine grit diamond bur, an adhesive bonding system should be applied to the acid etched composite substrate and adjacent tooth tissues and preparation margins, according to the manufacturer's directions; alternatively, a commercially available composite repair system (eg, Ecusit-Composite Repair, DMG, Chemisch-Pharmazeutische Fabrik GmbH, Germany; Clearfil repair kit, Kuraray, Tokyo, Japan), which includes its own specifically formulated adhesive agent, may be used

- apply resin composite restorative material using a $2 \mathrm{~mm}$ incremental technique to repair the defect; each increment must be polymerized using a visible light-curing unit; ideally, the same type and brand of resin composite material should be used as the composite substrate provided this information is known to the practitioner; the composite substrate must be a minimum $2 \mathrm{~mm}$ in thickness for the repair procedure to be successful

- carefully contour and finish the repair using contemporary composite finishing systems, to leave the repair integrated imperceptibly into the restored tooth unit

- check the occlusion and remove any occlusal interferences present.

The clinical procedure for the repair of a defective restoration of dental amalgam is as follows:

- local analgesia, as indicated clinically

- remove any undermined, unsupported tooth tissue and the surface of the amalgam restoration adjacent to the fracture to provide a fresh surface as a potential bonding substrate

- retention features may be prepared within the amalgam restoration to provide mechanical retention for the composite material

- ensure adequate moisture control by applying a rubber dam or judicious use of cotton wool rolls and salivary ejectors; either way, it is essential to achieve good moisture isolation

- prepare the adjacent amalgam and tooth tissue surfaces using either an intraoral aluminum oxide sandblaster (Microetcher) or a diamond bur

- if indicated, provide any necessary pulp protection according to contemporary regimes

- acid etch the tooth tissue surfaces for 15-30 seconds and thoroughly wash and dry the preparation using a three-in-one syringe

- apply an adhesive bonding system to the conditioned tooth surfaces according to the manufacturer's directions

- apply an alloy-resin bonding agent (eg, Alloy Primer, Kuraray) to the prepared amalgam surface according to manufacturer's directions

- as an optional step, a visible light-cure resin opaquer (eg, Visiogem, 3M ESPE) may be applied to the conditioned amalgam surface to mask the amalgam surface; the opaquer has a chemistry similar to that of the resin composite, and it chemically bonds to the alloy-resin bonding agent and resin composite material

- place the repair composite using an incremental technique, light-curing each increment fully prior to applying subsequent layers of material

- carefully contain and finish the repair, taking care to have burs and finishing devices work from composite to the amalgam

- check the occlusion and remove any occlusal interferences present.

\section{Success of repaired restorations}

So far, general dental practice-based prospective cohort studies have shown that repaired restorations in permanent teeth have the same or increased longevity compared with replacement restorations. ${ }^{31,33-35}$ Some of these dental practice-based studies have found repairs to remain clinically satisfactory over a 7-year observation period. ${ }^{25,34,35}$ A recent retrospective, general dental practice-based study has reported annual failure rates for repaired restorations of amalgam and composite to be $9.3 \%$ and $5.7 \%$, respectively. ${ }^{32}$ However, this study took into consideration the longevity of the repaired restoration, not the longevity of the repair itself.

The reasons why repaired restorations may outlast replacement restorations probably relate to the retention of those parts of restorations that have survived the "test of time", limiting the introduction of new elements that may compromise the success of the restoration. ${ }^{18}$ When "stress factors" related to restoration replacement are considered, 
including stress on the tooth, postoperative sensitivity, and re-exposure of the dentinal tubules with possible pulpal reactions to thermal or mechanical stimulus, ${ }^{36,37}$ damage to the adjacent tooth, and the possibility of more complex restorations, it makes perfect sense to give preference to the repair of a defective restoration as a predictable and minimally invasive approach to the preservation of tooth structure. A recent overview regarding restoration margins concluded that margin defects, without visible evidence of dentine on the wall or base of the defect, should be monitored, repaired, or resealed in preference to total restoration replacement. ${ }^{38}$

Besides being a successful treatment, restoration repair is also practical. Defective restorations can be repaired more rapidly and with lower operational costs than replacement. Adoption of refurbishment and repair procedures may profoundly change the present unsatisfactory situation of overtreatment of existing restorations. Furthermore, refurbishment and repair procedures offer a reduction in patient or third party payers' costs, with the latter creating an opportunity to address other dental treatment needs.

In summary, when examining and considering what action, if any, to take in respect of defects in existing restorations, first and foremost, consideration should be given to monitoring, refurbishment, and repair. Restoration replacement should be a last resort when there is no viable alternative. Gone are the days of looking at restorations with defects and thinking "why leave anything to doubt, just take it out".

\section{Disclosure}

The authors report no conflicts of interest in this work.

\section{References}

1. Mjör IA, Moorhead JE, Dahl JE. Reasons for replacement of restorations in permanent teeth in general dental practice. Int Dent $J$. 2000;50(6):360-366.

2. Mjör IA, Shen C, Eliasson ST, Richter S. Placement and replacement of restorations in general dental practice in Iceland. Oper Dent. 2002;27(2):17-123.

3. Gordan VV, Mjör IA, Blum IR, Wilson NHF. Teaching students the repair of resin based composite restorations: a survey of North American dental schools. J Am Dent Assoc. 2003;134(3): 317-323.

4. Blum IR. The management of failing direct composite restorations: replace or repair? In: Lynch CD, Brunton PA, Wilson NHF, editors. Successful Posterior Composites. London, UK: Quintessence Publishing Company; 2008.

5. Elderton R. Principles in the management and treatment of dental caries. In: Elderton R, editor. The Dentition and Dental Care. Oxford, UK: Heinemann Medical Books; 1990.

6. Kay E, Watts A, Paterson R, Blinkhorn A. Preliminary investigation into the validity of dentists' decisions to restore occlusal surfaces of permanent teeth. Community Dent Oral Epidemiol. 1988;16(2): 91-94.
7. Noar SJ, Smith BGN. Diagnosis of caries and treatment decisions in approximal surfaces of posterior teeth in vitro. $J$ Oral Rehabil. 1990;17(3):209-218.

8. Bader JD, Shugars DA. Understanding dentists' restorative treatment decisions. J Public Health Dent. 1992;52(2):102-110.

9. Frencken JE, Peters MC, Manton DJ, Leal SC, Gordan VV, Eden E. Minimal intervention dentistry (MID) for managing dental caries a review: report of a FDI task group. Int Dent J. 2012;62(5):223-243.

10. Bader JD, Shugars DA. Agreement among dentists' recommendations for restorative treatment. J Dent Res. 1993;72(5):891-896.

11. Burke FJ, Lucarotti PS. How long do direct restorations placed within the general dental services in England and Wales survive? Br Dent $J$. 2009;206(1):E2.

12. Bogacki RE, Hunt RJ, del Aguila M, Smith WR. Survival analysis of posterior restorations using an insurance claims database. Oper Dent. 2002;27(5):488-492.

13. Gordan VV, Riley JL 3rd, Geraldeli S, et al; Dental Practice-Based Research Network Collaborative Group. Repair or replacement of defective restorations by dentists in The Dental Practice-Based Research Network. J Am Dent Assoc. 2012;143(6):593-601.

14. Gordan VV. Clinical evaluation of replacement of Class V resin based composite restorations. J Dent. 2001;29(7):485-488.

15. Blum IR, Jagger DC, Wilson NHF. Defective dental restorations: to repair or not to repair? Part 1: direct composite restorations. Dent Update. 2011;38(2):78-80, 82-84.

16. Setcos JC, Khosravi R, Wilson NH, Shen C, Yang M, Mjör IA. Repair or replacement of amalgam restorations: decisions at a USA and a UK dental school. Oper Dent. 2004;29(4):392-397.

17. Hickel R, Peschke A, Tyas M, et al. FDI World Dental Federation clinical criteria for the evaluation of direct and indirect restorations. Update and clinical examples. J Adhes Dent. 2010;12(4):259-272.

18. Hickel R, Brüshaver K, Ilie N. Repair of restorations - criteria for decision making and clinical recommendations. Dent Mater. 2013;29(1):28-50.

19. Hickel R, Roulet JF, Bayne S, et al. Recommendations for conducting controlled clinical studies of dental restorative materials. Clin Oral Investig. 2007;11(1):5-33.

20. Blum IR, Newton JT, Wilson NHF. A cohort investigation of the changes in vocational dental practitioners' views on repairing defective direct composite restorations. Br Dent J. 2005; Suppl:27-30.

21. Sharif MO, Catleugh M, Merry A, et al. Replacement versus repair of defective restorations in adults: resin composite. Cochrane Database Syst Rev. 2010;2:CD005971.

22. Sharif MO, Merry A, Catleugh M, et al. Replacement versus repair of defective restorations in adults: amalgam. Cochrane Database Syst Rev. 2010;2:CD005970.

23. Blum IR, Schriever A, Heidemann D, Mjör IA, Wilson NHF. Repair versus replacement of defective direct composite restorations in teaching programmes in United Kingdom and Irish Dental Schools. Eur J Prosthodont Restor Dent. 2002;10(4):151-155.

24. Blum IR, Schriever A, Heidemann D, Mjör IA, Wilson NHF. The repair of direct composite restorations: an international survey of the teaching of operative techniques and materials. Eur J Dent Educ. 2003;7(1):41-48.

25. Blum IR, Mjör IA, Schriever A, Heidemann D, Wilson NHF. Defective direct composite restorations - replace or repair? A comparison of teaching between Scandinavian dental schools. Swed Dent J. 2003;27(3):99-104.

26. Blum IR, Lynch CD, Schriever A, Heidemann D, Wilson NHF. Repair versus replacement of defective composite restorations in German dental schools. Eur J Prosthodont Restor Dent. 2011;19(2):56-61.

27. Blum IR, Lynch CD, Wilson NHF. Teaching of the repair of defective composite restorations in Scandinavian dental schools. J Oral Rehabil. 2012;39(3):210-216.

28. Blum IR, Lynch CD, Wilson NHF. Teaching of direct composite restoration repair in undergraduate dental schools in the United Kingdom and Ireland. Eur J Dent Educ. 2012;16(1):e53-e58. 
29. Özcan M, Barbosa SH, Melo RM, Galhano GA, Bottino MA. Effect of surface conditioning methods on the microtensile bond strength of resin composite to composite after aging conditions. Dent Mater. 2007;23(10):1276-1282.

30. Blum IR, Hafiana K, Curtis A, et al. The effect of surface conditioning on the bond strength of resin composite to amalgam. J Dent. 2012;40(1): 15-21.

31. Gordan VV, Riley JL III, Garvan CW, Mondragon E, Blaser PK, Mjör IA. 7-Year results of alternative treatments to defective amalgam restorations. J Am Dent Assoc. 2011;142(7):842-849.

32. Opdam NJ, Bronkhorst EM, Loomans BA, Huysmans MC. Longevity of repaired restorations: a practice based study. J Dent. 2012;40(10):829-835.

33. Moncada G, Martin J, Fernández E, Hempel MC, Mjör I, Gordan VV. Sealing, repair and refurbishment of class I and class II defective restorations: a three-year clinical trial. J Am Dent Assoc. 2009;140(4): $425-432$
34. Gordan VV, Garvan CW, Blaser PK, Mondragon E, Mjör IA. A longterm evaluation of alternative treatments to replacement of resin-based composite restorations: results of a seven-year study. J Am Dent Assoc. 2009;140(4):1476-1484.

35. Gordan VV, Garvan CW, Richman JS, et al; The DPBRN collaborative group: how dentists diagnose and treat defective restorations: evidence from The Dental Practice-based Research Network. Oper Dent. 2009;34(6):664-673.

36. Hirata K, Nakashima M, Sekine I, Mukouyama Y, Kimura K. Dentinal fluid movement associated with loading of restorations. J Dent Res. 1991;70(6):975-978.

37. Bissada NF. Symptomatology and clinical features of hypersensitive teeth. Arch Oral Biol. 1994;39 Suppl:31S-32S.

38. Dennison JB, Sarrett DC. Prediction and diagnosis of clinical outcomes affecting restoration margins. J Oral Rehabil. 2012;39(4):301-318.
Clinical, Cosmetic and Investigational Dentistry

\section{Publish your work in this journal}

Clinical, Cosmetic and Investigational Dentistry is an international, peer-reviewed, open access, online journal focusing on the latest clinical and experimental research in dentistry with specific emphasis on cosmetic interventions. Innovative developments in dental materials, techniques and devices that improve outcomes and patient satisfaction

\section{Dovepress}

and preference will be highlighted. The manuscript management system is completely online and includes a very quick and fair peerreview system, which is all easy to use. Visit http://www.dovepress. com/testimonials.php to read real quotes from published authors.

Submit your manuscript here: http://www.dovepress.com/clinical-cosmetic-and-investigational-dentistry-journal 